It is a tribute to the compilers, however, that what they offer can rightly be claimed to be a reasonable consensus of the relevant medical community. To follow the guidelines would assure high quality care for all.

The arrival of this book coincided with that of the British Medical Journal of 16th April 1983 and its main editorial "Can't audit? Won't audit?", which hints that it is time peer auditing established quality assurance in the United Kingdom. British doctors, it states, are more reluctant to adopt such procedures than their counterparts in the USA. Having had personal experience of undertaking peer review visits to STD departments in both countries I found no difference. The American approach was more thorough, detailed, personal, and took days rather than hours. It is one of active involvement of all concerned in putting houses in order in the interests of STD control, as well as the care of the individual patient. This approach could have more influence and benefit worldwide than the British dedication to the concept of the centre of excellence matched with studied indifference to the persistently idle, often ignorant, and occasionally stupid practitioner.

It should at least be debated which approach offers the greater hope of fulfilling Bentham's dream of services to ensure the greatest good for the greatest number.

\section{R S Morton}

International perspectives on neglected sexually transmitted diseases-impact on venereology, infertility, and maternal and infant health. Edited by KK Holmes and Per-Anders Mårdh, 1983. Hemisphere Publishing Corporation, Washington, New York, London and McGraw-Hill Book Company. Pp 336. Price not known.

In addition to a World Health Organisation (WHO) scientific group on Neisseria gonorrhoeae and gonococcal infections (report published 1978, Tech Rep Ser 616, Geneva) and the more recent scientific group on treponemal infections (report published 1982, Tech Rep Ser 674), WHO also convened in 1978 a scientific group on non-gonococcal urethritis and other selected sexually transmitted diseases of public health importance, the report on which was published in 1981 (Tech Rep Ser 660 ). The full text of background documents reviewed by the scientific group has been now edited by the chairman (Seattle, USA) and the rapporteur (Lund, Sweden) and has been published privately.
The first section, on sexually transmitted agents (135 pages) covers Chlamydia trachomatis (J Schacter), Ureaplasma urealyticum and Mycoplasma hominis (F T Black), hepatitis B (R D Catterall), herpes simplex virus (L Corey), cytomegalovirus (D J Lang), Haemophilus ducreyi (A R Ronald, J C Wilt, and W L Albritton), Gardnerella vaginalis (W E Dunkelberg), Trichomonas vaginalis and other sexually transmitted protozoan infections (M Müller), and genital warts and ectoparasites (J D Oriel).

The second part (156 pages), which concerns syndromes and complications caused by sexually transmitted diseases, includes urethritis, epididymitis, and prostatitis in men (W Bowie), vaginitis, cervicitis, and urethritis in women ( $\mathrm{K} \mathrm{K}$ Holmes, who also writes the introduction), Lymphogranuloma venereum (A O Osoba), donovanosis (C N Sowmini), genital ulcers (P Wiesner with three colleagues from Centers for Disease Control, Atlanta), pelvic inflammatory disease (L Weström and P-A Mårdh from Lund, Sweden) and epidemiological aspects of infertility, which provides some particularly valuable illustrations and flow charts (M A Belsey, WHO, Geneva).

The third and shortest section (27 pages) on laboratory services covers laboratory diagnosis (E H Sng, Singapore) and simple, sensitive, and rapid diagnostic techniques (D Taylor-Robinson, London).

All those who read the excellent earlier WHO report, and will expect an amplification of similar calibre, will not be disappointed. The upshot is a must for the library shelf of all sexually transmitted disease clinics. As with other works published at this time, however, acquired immune deficiency syndrome (AIDS), which surely will be the subject of a WHO scientific group in the near future, has not yet made enough impact to merit inclusion in the index.

\section{$R$ Willcox}

Diagnosis and treatment of sexually transmitted diseases. Edited by $\mathbf{W} M$ McCormack, 1983. John Wright PSG Inc, Boston, London, and Bristol. Pp 260 including index. Price $£ 27$.

This book heralds a welcome new era in the study and treatment of sexually transmitted diseases in America. The editor has collected 19 well known authorities, including one from England, to write on the management of conditions which genitourinary physicians treat. As the editor states in the preface, the chapters are long on management and short on pathophysiology. $\overline{\mathrm{A}} \mathrm{s}$ might be expected from such a variety $\vec{\theta} f$ authors, style and imparting of knowlecge also vary considerably.

Some chapters should be mentioned the excellence of their contents. The chapters which are superb are those ofn urethritis in men by W R Bowie, epididymitis by $R$ E Berger, prostatitis by $W$. Sharer and W R Fair, vulvovaginitis and cervicitis by $M F$ Rein, the gay bow syndrome by D C William, and sexuatyy transmitted diseases in the paediat $\overrightarrow{\mathrm{E} F}$ patient by J I Santos and S Pelton. Mơt clinicians in practice for any length of time collect patients suffering from chron forms of urethritis, and the chapters on epididymitis and prostatitis alone make the purchase of this book worthwhile. Readimg the expositions in the long run can only hetp patient management. The British readgt will also learn some new terms, such gs orchalgia in the chapter on prostatitis amd the STORCH syndrome (venereal infetions acquired in utero) in the chapter of sexually transmitted diseases in the paed. iatric patient.

Probably because of the high costs of laboratory investigation in private practice, considerable importance is given to labo atory procedures which clinicians ca্ perform themselves. It would aid the oft spoilt junior doctor in the United Kingdof to read the beautiful description of micre scopic examination of vaginal specimens the chapter on vulvovaginitis and cervicitis by $M$ F Rein, where the reader will also find first rate illustrations of vaginal wet mounts. Even the chapter on scabies by Orkin and $\mathrm{H}$ I Maibach is worth reading learnt a new way to hunt for the acarus, the Burrow ink test. You'll have to read the chapter yourself to learn how to do it.

Apart from a few American interpretations of English which read curiously of the eastern side of the Atlantic, this is entertaining and informative book, and as practical guide will amply justify purchase.

Michael Waugh

Pathogenesis and immunology ơf treponemal infection. Edited by R F Schell and D M Musher, 1983. Marcel Dekk\&, New York. Pp 424. Price £52.

As data on the experimental patholog biochemistry, and immunology of treponemal infections accumulate, it is valuabe 